\title{
The Production of Yes/No Questions, Wh-Questions, and Embedded Clauses as Functional Categories at the Initial Stage of Child L2 Acquisition
}

\author{
Mohsen Mobaraki \\ Department of English, University of Birjand, Iran \\ Email: mmobaraki@birjand.ac.ir \\ Amin Saed (Corresponding author) \\ Department of English, Chabahar Maritime University, Iran \\ E-mail: Amin.saed@cmu.ac.ir
}

Received: 05-06-2016

Published: 02-01-2017
Accepted: 29-08-2016

doi:10.7575/aiac.ijalel.v.6n.1p.39
Advance Access Published: November 2016

URL: http://dx.doi.org/10.7575/aiac.ijalel.v.6n.1p.39

\begin{abstract}
This is a longitudinal case study of two Farsi-speaking children learning English: 'Bernard' and 'Melissa', who were $7 ; 4$ and $8 ; 4$ at the start of data collection. The research deals with the presence or absence of functional categories (CP),in our case Yes/no questions, Wh-questions, and embedded clauses as well as their production rate in early stages of interlanguage development of the child second language (L2) acquisition of syntax. Some studies in the field of child second language acquisition regarding the production of functional categories $(\mathrm{CP})$ are discussed. Examining data collected from the children's spontaneous speech, the researcher's diaries and translation and other tasks over a period of 20 months, the competing claims of the two most prominent hypotheses about early L2 grammars are tested: Vainikka\& Young-Scholten's (1996) Minimal Trees/Structure Building hypothesis and Schwartz \& Sprouse's (1996) Full Transfer/Full Access hypothesis. The conclusion is reached that Yes/no questions, Wh-questions, and embedded clauses as three functional categories are absent in early stages of interlanguage development of the child L2acquisition.
\end{abstract}

Keywords: Functional categories, Child L2 acquisition, Minimal Trees/Structure Building hypothesis, Full transfer/full access hypothesis, Yes/no questions and Wh-questions, Embedded clauses

\section{Introduction}

There has been considerable debate during the last several decades regarding child and adult second language acquisition of morpho-syntax in a naturalistic environment to find the source of knowledge responsible for the developmental stages observed in the data provided from the learners in those studies. While all these hypotheses of initial second language (L2) acquisition claim that the initial state is a specific grammar involving the first language (L1) grammar, the existence of functional categories in the learners' initial state productions, the extent of L1 involvement in the process of L2 acquisition, the reason behind the omission of verbal inflection and use of nonfinite forms in finite contexts, and the morphology/syntax relationship are among those issues left unresolved. The present research is based on L2 English data collected longitudinally from two L1 Farsi children to investigate the mechanisms involved in the learners' development. The data will be discussed in the light of some of the studies discussed in child and adult second language acquisition syntax. This study hopes to be able to show which of the adult second language hypotheses is on the right track with regard to the issues mentioned through comparing the result of the present study with those of all these studies. This study aims at addressing the status of functional categories (CP) in B and M's early L2 English. Similar to L1 acquisition studies, L2 acquisition studies have been the subject of considerable recent debate regarding the presence or absence of functional categories in early stages of interlanguage development. According to some authors, both lexical and functional categories are present in early L2 acquisition, whereas for some others only lexical categories and their projections are initially present. This study addresses the status of CP in L2 acquisition through looking at Yes/no questions, W-h questions, and embedded clauses focusing on Vainikka \& Young-Scholten's (V \& Y-S) (1996)Minimal Trees/Structure Building hypothesis and Schwartz \& Sprouse's (1996) Full Transfer/Full Access hypothesis (FT/FA) to see if these claims which are based on adult and child L2 acquisition, respectively, are supported by the data obtained in the present study.

\subsection{Research questions}

1. How is CP (Yes/no questions, W-h questions, and Embedded clauses) developed in English L2 acquisition?

2. Is there any trace of $\mathrm{L} 1$ transfer? 


\section{Review of the related literature}

The term 'initial state' which was largely neglected from the mid 1970s to the early 1990s refers to the unconscious linguistic knowledge L2 learners start with. Differences between child L1 and child L2 acquisition, the issue of L2 initial state and the extent of L1 influence have been addressed in a number of studies since then (Eubank 1996, Hawkins 2001, Schwartz \&Sprouse 1996, Vainikka and Young Scholten 1994, 1996a, 1996b; 2005,). These studies are mainly concerned with L1 influence in adult L2 acquisition but there are also studies dealing with L2 children in this regard (Haznedar 1997, Lakshmanan 1993/1994, Lakshmanan 1994, Lakshmanan and Selinker 1994, Unsworth 2005)

There are many proposals regarding the acquisition of functional categories in child language. According to the maturational hypothesis, child grammars initially project only lexical categories and functional categories develop maturationally (Guilfoyle \& Noonan 1992, Lebeaux 1989, Ouhalla 1991, Platzack 1990, Radford 1990, Tsimpli 1992). Syntactic properties related to functional categories are absent in the speech of children and early grammars are different from adult grammars. Radford's (1990, 1992, and 1995) 'small clause' hypothesis is based on this hypothesis.

Early studies in the domain of CP in child L1 English, by e.g. Brown (1968), Klima, and Bellugi (1966) stated that auxiliary emergence and inversion appears in yes/no questions before wh-questions. Moreover, inversion was found to be more productive in affirmative wh-questions compared to negative ones. According to Brown (1968), the reason behind the inability to invert subject and verb is due children being limited in their transformations used in utterances. They are able to do wh-fronting, but not subject-auxiliary inversion. Two decades later, Radford (1990) argues that children's early questions lack a CP system. He found no evidence regarding auxiliary movement to C or Wh-phrase movement to the Spec CP:

While there are many studies concerning the role of functional categories and L1 influence in the area of adult L2 acquisition, only a few studies have dealt with children in this regard. Lakshmanan and Selinker (1994) studied the development of CP in child L2 English and stated that CP is present at the earliest stages. They analyzed the CP production of Marta, a 4 and half year old Spanish child originally studied by Cancino et al. (1978), and Muriel, a 4year-old L1 French child based on Gerbault's (1978) study. L \& S observed that both children used embedded clauses very early. Regarding Marta's data, it seems that she had had exposure to English before going to the USA and before data were collected as well, and her grammar does not refer to the initial states. Neither of the children used complementisers that in their data, therefore, there was no trace of L1 transfer as both French and Spanish require overt complementisers in the embedded clauses.

Haznedar (1997) examines the status of the functional categories in the child second language acquisition of English. The subject of the study is a native speaker of Turkish called Erdem who had arrived in the UK in November 1993. He was $4 ; 3$ at the time of the start of data collection. He had no exposure to English prior to his arrival in the UK as well as during the first two months of his stay, for he was at home with his Turkish-speaking parents. The data analyzed in this study consist of 46 recordings, covering a period of 18 months. Haznedar considers the presence or absence of functional categories (IP and CP).She concludes that functional categories are present at the initial state of L2 acquisition.

In another study Haznedar\& Schwartz (1997) \&Haznedar (2001) observed that while the child produced many nonfinite forms in his speech, he stopped omitting subjects long before the use of verbal inflection in obligatory context. This led to the conclusion that there is no relation between the use of inflectional morphology and overt nominative subject, auxiliary movement and subject raising.

\section{Methodology}

The spontaneous data in this study are based on oral production gathered longitudinally from two Farsi-speaking children, Melissa 7;4 and Bernard 8;4 (sister and brother; from now on in this study M \& B) who at the start of data collection had not been exposed to English upon their arrival in the UK. They lived in university student family accommodation where there were many native and nonnative children available to talk to. They started going to an English school for six hours a day immediately after their arrival. There were no other Farsi speaking children in that school and they had to interact in English during six hours of school each day. Their father (the present researcher) was a PhD student in the UK at the time of the study and they expected to stay in the UK at least for three years. Their physical and mental development was age-consistent and they did not suffer from any speech or language impairments. At home, they watched British television and became interested in reading different kinds of books in English. Data collection started about 50 days after the learners' arrival and the learners can be considered as being in their initial states of L2 acquisition. Since the researcher was not a native speaker of English, two native speakers who were teachers as well as linguistics students at the time helped him in the data collection process. The data were collected for 20 months. The type of data includes spontaneous (S), Translation (T), or diary (D). Audio-recordings were made roughly once a week, but sometimes every other week or even once a month when the assistants were away. Recording would start after five or ten minutes of greetings and warm-up. Each recording varied in length from 90 to 120 minutes. 41 samples (S) were audio-recorded, transcribed and analyzed.

\section{Findings}

\subsection{Yes/no questions}

The counting procedure and categorization in yes/no questions are as follows. All questions have been divided into correct suppliance, incorrect suppliance, and wrong raised. Excluding two sentences produced by M in Samples 3 and 4 
through using intonation, there are no yes/no questions up to Sample 9. The first yes/no questions in the IP stage occur in Sample 14 where five out of five questions are formed without any inversion. Regardless of some rote-learned questions produced before Sample 20, it is from this sample on that the learners start to invert the subject and the verbs but at the same time, the rate of incorrectly-inverted verbs increases as (1) shows. This is where the CP seems to project in the learners' grammars.

(1) a. B: Are you went alone? (S 22)

b. M: Is your elephant have a name? (S 24)

c. M: Is your elephant have three tail? (S 24)

d. B: Is they like a people? (S 24)

e. M: Is your children \# are naughty? (T 26)

f. B: Does the sun is shining? (T 26)

g. B: Do you can open the door? (T 26)

h. B: Is daddy's shirt is blue? (D 28)

i. M: Is my book and notebook are blue? (D 28)

From Sample 28 on, the rate of wrongly-inverted questions decreases and this is where the correct suppliance of yes/no questions increases rapidly. It is from this sample on that the fluctuations in yes/no questions with auxiliaries, copula forms or modals gradually decrease so that the rate of target production reaches $100 \%$ for both learners by Sample 33:

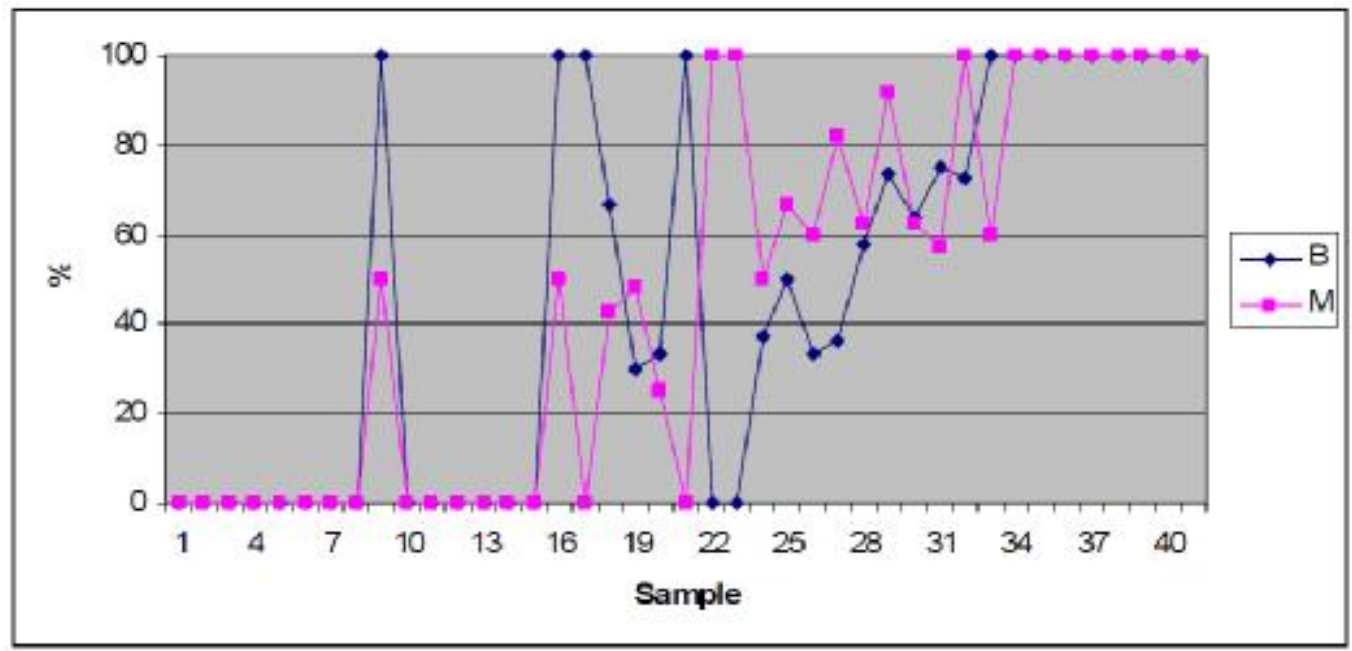

Figure 1. Percentage of correct yes/no questions

(2) a. B: Do you know what a brain gym is? (S 29)

b. M: Can you make food? (S 30)

c. B: Is it sweet or something? (S 32)

d. M: Are they making snowman? (T 33)

It is between Samples 14 and 18 that the production of copula is almost always target-like and there is a low fluctuation in the learners' productions in this regard. Yes/no questions appear after the learners have acquired the copula. Since the acquisition of the copula in this study is proposed to trigger IP, target-like yes/no questions are produced after the learners have IP in their grammars. There are only seven target-like questions out of 54 (12.96\%) produced before Sample 18, and these are all cliché forms. This indicates that the learners have acquired IP before CP is projected in their grammars.

\subsection{Wh-questions}

Regarding the counting procedure and categorization for wh-questions, all questions were divided into correct suppliance, incorrect suppliance, and wh-in-situ. Regardless of the rote-learned wh-questions that were produced in Samples 8 and 9, there is no subject-verb inversion in early samples and early wh-questions are wh-in-situ. The following sentences show the lack of agreement between subject and the auxiliary verb and overgeneralization of $i s$, is evident in early wh-questions: 


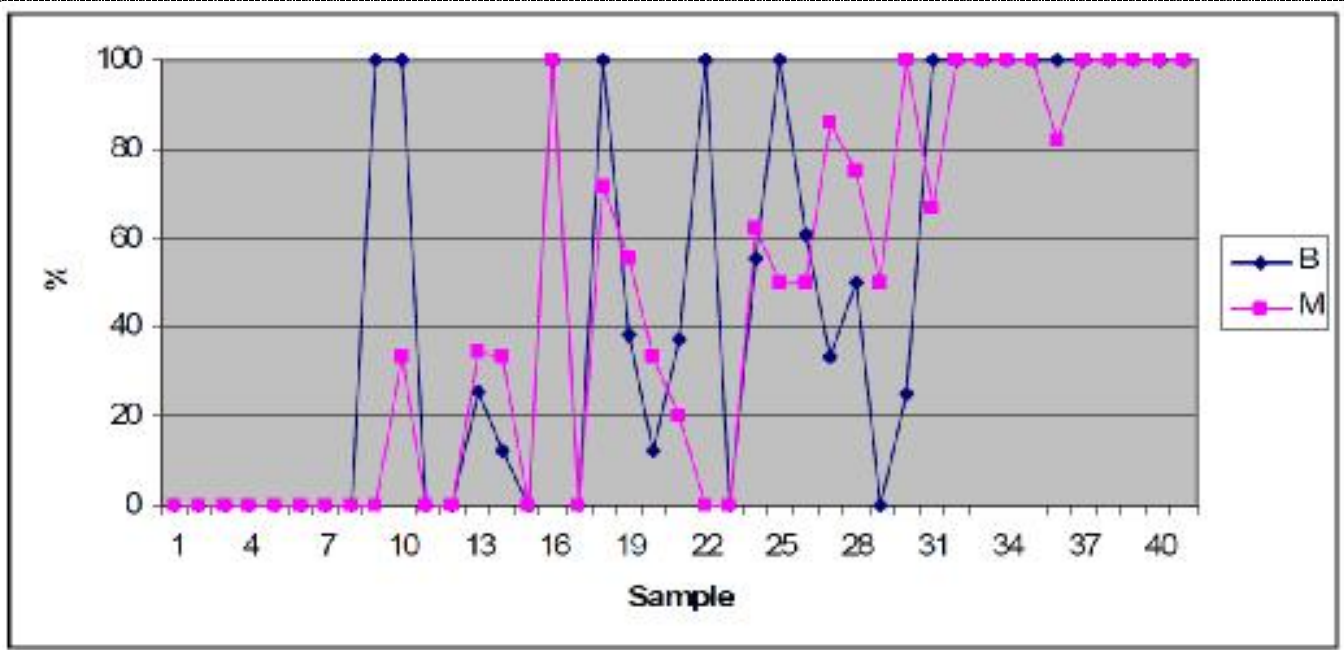

Figure 2. Percentage of correct wh-questions

(3) a. B: Where is books? (T 13)

b. M: Where is the books? (T 13)

c. B: Who is they? (T 13)

d. M: Where is spoons? (T 13)

e. B: You where is go? (T 14)

f. M: Where is I am? (T 19)

g. B: Where is they are? (T 19)

h. M: Where is they are? (T 19)

The above examples show that $\mathrm{CP}$ is not projected in the early stages and the raising of wh-question words followed by $i s$ is a rote-learned form.It is also observed that $d o$-insertion is acquired after auxiliary inversion. There are 77 obligatory contexts for $d o$ insertion up to Sample 26.and there are only 9 (11.68\%) questions where auxiliary $d o$ has been inserted (4a-d) and the other sentences are missing this auxiliary (4e-h).

(4) a. B: What do you like? (T 13)

b. M: What colour do you like? (T 13)

c. M: What do you want? (T 19)

d. B: How many people does Iran have? (S 21)

e. M: It have a long nose? (D 20)

f. M: We have just big star? (D 21)

g. B: They can fly? (S 24)

h. B: You say cat like water? (S 25)

Similar to Klima and Bellugi (1966), I also observed that inversion is more productive in affirmative wh-questions compared to negative ones. Although there are only six negative wh-questions in the whole study, in none of them has the auxiliary been inverted:

(5) a. B: Why you don't eat it? (S 17)

b. M: Why you don't like it? (S 17)

c. M: Why you didn't clean the step? (S 19)

d. B: Why you don't have a mouse? (S 24)

e. B: Why you didn't go to this, this, this? (S 24)

f. B: Why Morocco is not expensive? (S 24) 
It was also observed that the learners did not distinguish subject wh-questions from non-subject wh-questions and they inserted auxiliaries where not needed. There are only 12 subject wh-questions out of 432 in the whole study and in five the auxiliary is was wrongly inserted:

(6) a. B: Who is everyday buy the bread? (T 19)

b. B: Who is go to school everyday? (T 19)

c. B: Who is eat the lunch everyday? (T 19)

d. B: Who is water the garden? (T 26)

e. B: Who is broke the window? (T 26)

This shows that auxiliary is is over generalised in interrogative as well as declarative sentences. Moreover, just as in declarative sentences, auxiliary be is the first one which is fixed in the learners' wh-questions and auxiliary do emerges later (see example 4). It seems that it is after Sample 22 that the percentage of correct wh-questions increases so that by Sample 31 the correct production reaches to $100 \%$.In the next section, the production of another CP-related element, embedded clauses will be discussed.

\subsection{Embedded clauses}

Another CP-related element to discuss in this chapter is the embedded clauses. Clauses including because and if will be discussed first. Second, the use of infinitival clauses will be taken into account. In early embedded clauses with because either the head or specifier of IP is empty. After Sample 16, the rate of target-like embedded clauses rapidly increases so that there are no non-target-like embedded clauses with either if or because by Sample 18:

(7) a. M: Because the bee sting him. (S 17)

b. B: Because is black. (S 17)

c. M: Because elephant is very big. (S 18)

d. B: Because I don't like you ask we questions. (S 19)

e. M: Because the cow like him, I think. (S 20)

The first if clauses occur in Sample 24. All if clauses produced are target-like:

(8) a. B: If you wish whatever you like, he bring it to you. (S 24)

b. M: If he is a baby why you take him here? (S 24)

c. M: If you say my English is better, B cross. (S 25)

d. B: If it was a name, I didn't lost it. (S 29)

Complement clauses with wh-clauses are the other CP-related elements to be discussed here. These clauses first appear in Sample 15. The chunk form of 'where is' in the following sentences again show the CP is not present:

(9) a. B: No, I am \# I don't know mum where is. (S 15)

b. M: I don't know B where is. (S 15)

c. M: I don't know where is your book. (S 15)

d. M: Do you know what am I doing? (S 18)

e. B: I don't know what his name. (D 22)

\subsection{Infinitival to}

Another CP-related element is the production of infinitival clauses. As mentioned in 5.2, the first obligatory context for the infinitival to is in Sample 16, but there is almost no to appearing up to Sample 18, where IP projected in both learners' grammars. It was after Sample 18 that the obligatory context increased and this construction turned to targetlike in the production of both learners. From Sample 19 up to Sample 40, B produced 83 utterances and except three sentences in Samples 19 and 20 (10a-c), all sentences were target-like:

(10) a. B: Because he wanted bring it his towel. (S 19)

'Because he wanted to bring his towel.' 
b. B: Because I don't like you ask we questions.' (S 19)

'Because I don't like you to ask us questions.'

c. B: I don't like go to school tomorrow. (S 20)

d. B: Girl like to play with girl. (S 25)

e. B: I want to be a Football player. (S 30)

M produced 97 sentences from Sample 19 up to Sample 41 and all the sentences were target-like:

(11) a. M: He want to buy the book to read. (S 20)

b. M: Oh look! I want to show you something. (S 28)

c. M: I want to be a doctor. (S 31)

d. M: I want to give you apple. (S 36)

The above examples (target-like CP after Sample 18) all show the emergence of CP after IP, although it seems that infinitival clauses become target-like earlier than yes/no and wh-questions.

\section{Discussion}

Let us start the discussion with respect to the FT/FA hypothesis which claims that CP is present in the initial states of L2 acquisition and the properties are transferred from the L1. The first CP-related element discussed in this article is yes/no questions. I already discussed that early questions made are mainly tonic and the learners start to invert the subject and verb after they project IP. The early inverted questions are also non-target-like and there is no evidence to show that CP is projected. This is exactly the same as what Haznedar (1997) observes in her study that Erdem does not regularly produce questions. Despite this, Haznedar claims that CP is present in the initial states because Erdem was able to comprehend and process sentences with CP. This is not the same as what I observed in the present study. There are many instances where the learners respond yes or no just to stop the investigator asking more questions and their judgment on the question is just based on the meaning of some of the words in the sentence. This indicates that although the learners may answer some cliché form questions memorized as a result of repetition, they have problems to answer unexpected questions. This shows how limited their comprehension at the early stages is. This provides counter evidence for Grondin\& White's (1996) study on the acquisition of French by two English-speaking children in which the children provided answers to wh-questions.

The second CP-related element discussed here was wh-questions. It was observed that wh-fronting precedes subjectauxiliary inversion. This primarily shows that unlike Farsi, which is a wh-in-situ language, early wh-questions are not in-situ, which indicates that no L1 transfer is involved. Haznedar, on the other hand, states that the absence of early insitu wh-questions in Erdem's speech represents a transfer effect as Turkish does not allow Wh-phrases to occur in post verbal position. This is misleading. Neither English nor Turkish grammar allows this, so it does not have anything to do with transfer because there is no reason for Erdem to produce such utterances. It was also observed that there is no subject-auxiliary inversion because the auxiliaries are not present at the initial stages to be inverted. If the CP projection were present in accordance with the FT/FA hypothesis, assuming that allwh-phrases move to Spec-CP, it is not clear why the auxiliary did not move to Comp.

Bhatt \& Hancin-Bhatt (2002) conducted a study regarding the status of CP at the initial state. The subjects of the study were 125 (25 in each grade) Hindi L1s learning English L2 in a public school in New Delhi across five grade levels. In line with the present study, the results of their study also show that wh-fronting precedes aux-inversion. It was also observed that the learners at the initial stages are unable to distinguish subject wh-questions from non-subject whquestions by inserting auxiliaries where not needed. This indicates that Aux inversion at the initial stages happens randomly. Haznedar (1997) argues against V \& Y-S's MTH by claiming that V \& Y-S predict the root subject whquestions are acquired first as movement is impossible due to lack of CP projection. First, there is not such a prediction as far as I know. Second, the learners insert and invert the Aux even in subject wh-questions whereas their non-subject wh-questions lack inverted Aux at the same time. This, to me, means that CP is not projected. Absence of target-like embedded clauses at the initial stages also provides counter evidence for FT/FA hypothesis. Either the head or specifier of IP in all the early embedded clauses with ifand because is empty and casts doubt on the idea thatbecause is really in the CP. The initial infinitival clauses also lack the infinitive marker $t o$, whereas at the later stages this marker is $100 \%$ present in the production of the learners. Following V \& Y-S the mere presence of copula indicates that learners project an underspecified IP-level functional projection since despite the presence of copula there is a lack of an agreement paradigm for that. 


\section{Conclusion}

The empirical considerations noticed in this article indicates that in contrast to the FT/FA hypothesis, the early L2 grammars of the two children in this study do not provide any evidence for the projection of CP. The result was obtained through looking at the two learners' yes/no questions, wh-questions, and embedded clauses including because and if produced in the early stages and comparing it with those produced in later stages. The earliest productions on both yes/no and wh-questions indicate that the learners neither comprehend the early questions exactly, nor can they produce target-liked questions where the Aux is inverted. The only questions comprehended at the start are those repeated a lot and memorized by the learners as chunks. If there is a bit change in the structure of the questions made, the learners will get them wrong.

Moreover, they take questions as questions if there is a rising intonation, and the same sentences without rising intonation will be taken as declarative sentences at the early stages. This argues against Haznedar who takes the mere response to some yes/no questions as an indication for CP projection. The researcher also observed that from Sample 20 on the learners start to invert the Aux and this reaches to $100 \%$ by Sample 33, which is significantly later than when IP was fixed (around Sample 18) in their grammars. This means that the learners have acquired IP before CP is projected in their grammars and supports structure building regarding the initial stages in adult L2 acquisition, on one hand, and provides counter-evidence for FT/FA hypothesis which claims the early grammars project CP, on the other. This study also shows that different data collection methods can influence the rate of producing questions and data acquired through D and T provide a clearer picture of the initial state and the initial grammar better than what spontaneous data often do. Regarding wh-question formation, despite the fact that Farsi is a wh-in-situ language, there is not even one question in the whole corpus where wh remains in-situ in questions produced spontaneously, whereas all the questions made during translation tasks are in-situ. This again shows how the data collection method can affect results and emphasizes the unanalyzed nature of early wh-questions.

Following Brown's (1968) study of child L1 acquisition, I also observed that wh-fronting precedes subject-auxiliary inversion. To me, this may be due to the absence of Aux at the early stages that affects the production of questions as well. I also found that $d o$-insertion was acquired after auxiliary inversion. Early embedded clauses are not target-like as well, which is more evidence for lack of CP prior to IP. Although there are some clauses including because and if in the early samples, the head or specifier of IP in these clauses is empty, which shows that these elements have not been raised to $\mathrm{CP}$, whereas later samples show that the learners project CP. Although embedded clauses emerge after IP has been projected in the learners' grammars (around Sample 20) which confirms the earlier proposal made in this study that CP follows IP, they were present quite before the time that questions emerged in the study. This indicates that some properties of CP may emerge later than others that depend on the nature of the construction under discussion and the present study has found no reason behind this. This is the same with wh-embedded clauses which emerge around Sample 19 just after the learners have fixed IP in their L2 grammar. To summarize, this study shows that the functional category CP is not present at the initial stages of L2 acquisition and emerges after the learners have mastered IP in their grammars. It also shows that unlike Farsi, which is a wh-in-situ language, early wh-questions are not in-situ, which indicates that no L1 transfer is involved.

\section{References}

Bhatt, R.M., \& Hancin-Bhatt, B. (2002).Structural Minimality, CP and the initial state in second language acquisition. Second Language Research, 18(4), 348-392.

Brown, R. (1968). The development of Wh-questions in child speech. Journal of Verbal Learning and Verbal Behaviour, 7, 279-290.

Cancino, H., Rosansky, E.J. \& Schumann, J.H. (1978). The acquisition of English negatives and interrogatives by native Spanish Speakers. In E.M. Hatch (ed.).

Eubank, L. (1996). Negation in early German-English interlanguage: More valueless features in the L2 initial state. Second Language Research, 12, 73-106.

Gerbault, J. (1978). The acquisition of English by a five year old French speakers. Master's thesis, University of California at Los Angles.

Grondin, N. \& White, L. (1996). Functional categories in child L2 acquisition of French. Language Acquisition, 5,1-34.

Guilfoyle, E. \& Noonan, M. (1992).Functional Categories and Language Acquisition. Canadian Journal of Linguistics, $37,241-272$.

Hawkins, R. (2001). Second language syntax. A Generative Introduction. Oxford, Blackwell.

Haznedar, B \& Schwartz, B.D. (1997).Are there Optional Infinitive in child L2 acquisition? In E. Hughes, M. Hughes \& A. Greenhill (eds.). Proceeding of the 21st Boston University Conference on Language Development. Somerville, MA. Cascadilla Press PP. 257-268.

Haznedar, B. (1997). Child second language acquisition of English. A Longitudinal Case Study of a Turkish-Speaking Child, PhD dissertation, University of Durham, UK.

Haznedar, B. (2001). The acquisition of the IP system in child L2 English. Studies in second language acquisition, 23, 1-39. 
Klima, E. \&Bellugi, U. (1966).Syntactic regularities in the speech of children. In J. Lyons \& R.J. Wales. (eds.) Psycholinguistic Papers. Edinburgh: Edinburgh University Press, 183-208.

Lakshmanan, U. \&Selinker, L. (1994).The status of CP and the tensed complementizer that in the developing L2 grammars of English. Second Language Research 10, 25-48.

Lakshmanan, U. (1993/94). The boy for the cookie'-Some evidence for the non violation of the Case Filter in child second language acquisition. Language Acquisition, 3(1), 55-91.

Lakshmanan, U. (1994). Universal Grammar in Child Second Language Acquisition: Null subjects and morphological uniformity. Amsterdam: John Benjamins.

Lebeaux, D. (1989). Parameter-setting, the acquisition sequence, and the form of the grammar: The composition of phrase structure. Paper presented at GLOW. Utrecht.

Ouhalla, J. (1991). Functional categories and parametric variation. London: Routledge.

Platzack, C. (1990). A grammar without functional categories: A syntactic study of early Swedish child language. Nordic Journal of Linguistics, 13, 107-126.

Radford, A. (1990). Syntactic Theory and the Acquisition of English Syntax. Oxford: Basil Blackwell.

Radford, A. (1992). The acquisition of morphosyntax of finite verbs in English. In Meisel, J., (ed). The acquisition of verb placement. Dordrecht: Kluwer, 1-22.

Radford, A. (1995). Children: Architects or Brickies? In D. MacLaughlin\& S. McEwen (eds.). Proceedings of BUCLD 19, 1-19.

Schwartz, B.D. \&Sprouse, R.A. (1996).L2 cognitive states and the Full Transfer/Full Access model.Second Language Research, 12(1), 40-72.

Tsimpli, I.M. (1992). Functional Categories and Maturation: The Prefunctional Stages of Language Acquisition. University College London Working Papers in Linguistics, 3,128-198.

Unsworth, S. (2005). Child L2, Adult L2, Child L1: Differences and Similarities. A study on the acquisition of direct object scrambling in Dutch.PhD thesis, Utrecht University.

Vainikka, A. \& Young-Scholten, M. (1994). Direct access to X-bar theory: Evidence from Korean and Turkish adults learning German. In T. Hoekstra \& B.D. Schwartz (eds.) Language Acquisition Studies in Generative Grammar. Amsterdam: John Benjamins. 265-316.

Vainikka, A. \& Young-Scholten, M. (1996a). Gradual development of L2 phrase structure. Second Language Research, 12(1):7-39.

Vainikka, A. \& Young-Scholten, M. (1996b). The early stages in adult L2 syntax: Additional evidence from Romance speakers. Second Language Research, 12(2),140-176.

Vainikka, A. \& Young-Scholten, M. (2005).The roots of syntax and how they grow.Organic Grammar, the Basic Variety and Processability Theory. In S. Unsworth, A. Sorace, T. Parodi and M. Young-Scholten (eds). Paths of Development in L1 and L2 Acquisition. Amsterdam: Benjamins. 